\title{
Maximum Power-Point Tracking and Stall Control with Eddy Current Brake System on Small-Scaled Wind Turbines and its Application on Agricultural Harvesting
}

\author{
Anupa Koswatta $^{1}$, Faramarz Alsharif ${ }^{2}$, Yasushi Shiroma ${ }^{1}$, Shiro Tamaki ${ }^{1,}$, Junji Tamura ${ }^{2}$ \\ ${ }^{1}$ Graduate school of Engineering, University of the Ryukyus, 903-0213, Japan \\ ${ }^{2}$ School of Earth, Energy and Environmental Engineering, Kitami Institute of Technology, 090-8501, Japan
}

\begin{tabular}{l} 
A R T I C L E I N F O \\
\hline Article history: \\
Received: 21 May, 2020 \\
Accepted: 21 June, 2020 \\
Online: 12 July, 2020 \\
\hline
\end{tabular}

Keywords:

Small-scaled Wind Turbine

MPPT control

Eddy current brake

Over-rotation

Strong wind

\begin{abstract}
A B S T R A C T
This research aims to enhance the generated power of the small-scaled wind turbine using the eddy current brake system and Maximum Power Point Tracking (MPPT) control method. We analyzed the behavior of the generated power and power factor, with and without the MPPT control which implemented by eddy current brake system. Also, the feasibility of the system investigated using different wind conditions such as strong and calm wind conditions. The load data has different voltage respond to the system since its conditions depend on the day/night loads pattern, weather conditions, soil moisture. Moreover, the analogical experiment for small-scaled wind turbine blade destruction is analyzed to determine the maximum penetration value of mechanical power in order to retrieve an optimal angular velocity which resulting in provides a possible maximum power to loads. At the same time, emergency break is operated when angular velocity reaches to critical speed to avoid destruction. In the simulation, we collected the real load data from a mango farm in Okinawa prefecture in Japan. The results were analyzed through simulations for the different wind conditions. In the end of simulation, we could verify that either Maximum Power Point and emergency control are activated correspondingly.
\end{abstract}

\section{Introduction}

As a renewable energy generating equipment, small-scaled wind turbines have rising demand to fulfill the modern energy requirements. The small-scaled wind turbines have several merits such as less area needed for setting up the entire system, low cost maintenance and easy to assemble which are advantages for household use [1]. Comparing to the conventional large-scale wind turbines, small-scaled wind turbines produces small amount of power while large scale wind turbines produces maximum $8 \mathrm{MW}$ power. Therefore small-scaled wind turbines are suitable for household and small-scaled green houses and farms.

To supply a stable electricity output, small-scaled wind turbines uses several control methods such as pitch control [2-3], yaw control, brake control [4-6]. Considering brake control, it is mainly focus on brake pad-based system for the safety of the wind turbine [7] while contactless brake systems related research is ongoing currently. In [8] we proposed to realize a contactless angular velocity in emergency case by eddy current method,

${ }^{*}$ Corresponding Author: Shiro Tamaki, shiro@ie.u-ryukyu.ac.jp however, the optimal control was not concerned. In this research, we are focusing to enhance the power through maximum power point tracking (MPPT) using eddy current brake system and eddy current brake system for emergency rotational control.

Since the wind speed stability is always unpredictable, it is a difficult task to generate the maximum power continuously and keep the generated power in a stable state. In this regard MPPT control can be considered as an important controlling method to generate the maximum power. Many types of MPPT control methods are used for generating maximum power such as using fuzzy logic controllers [9], adaptive control [10], etc. In this research, we use the eddy current brake as the main controller tool for the MPPT control. Here, MPPT operation is to convey the maximum possible power from turbine to generator. Therefore, this operation contains power enhancement characteristics. Meanwhile, emergency break is implemented as well to avoid any destruction or malfunction of entire system since small-scaled wind turbine's angular velocity rise up drastically during the high wind penetration. 
In this study, the mango green house is a mango cultivating farm where the location is in Okinawa, Japan. The mango plants are required to be grown in a controlled environment in order to make best condition for cultivating. Also, the conditions are monitored using Internet of Things (IoT) technology. Therefore, the farmer can analyze the real time mango plants conditions such as its soil moisture, farm temperature, $\mathrm{CO}_{2}$ conditions, light conditions and humidity.

In this paper, first we explain about the structure of the proposed system including proposed brake system, control diagram, simulation block diagram. Next, we explain the mathematical modeling of the system. Afterwards, we describe the simulation and results. Finally, we describe the conclusion of our research. This research is an extended work of [11].

\section{Blade destruction analysis}

This section explains the analogical experiment of the blade destruction. We performed this experiment to analyze the blade destruction for different penetration values. In other words, we did this experiment to decide the safety margins of the small-scaled wind turbine. In Figure 1, the experimented broken small-scaled wind turbine blade is displayed. In the following equation (1) $F_{\max }$ means the maximum allowable force on the wind turbine blade and $m$ means the mass of the turbine's blades. Also, $\omega_{\max }$ represents the blade destruction angular velocity. Table 1 shows the specification of the blade. The material of the blade is made using Fiber Reinforced Plastic (FRP).

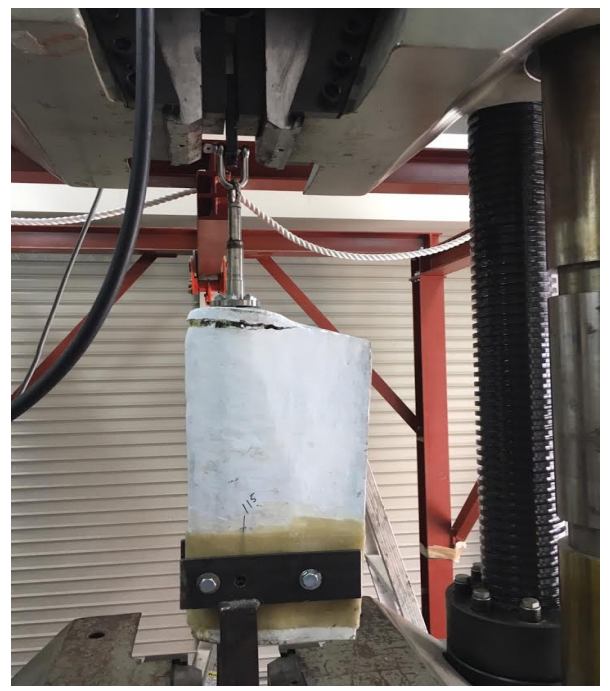

Figure 1. Broken wind turbine blade

$$
F_{\text {max }}=\operatorname{mr\omega }_{\text {max }}^{2}
$$

Table 1. Specification of the blade

\begin{tabular}{|c|c|c|}
\hline Parameter & Value & Unit \\
\hline $\mathrm{F}_{\max }$ & 4.5 & $\mathrm{kN}$ \\
\hline $\mathrm{m}$ & 2.57 & $\mathrm{~kg}$ \\
\hline $\mathrm{r}$ & 2.5 & $\mathrm{~m}$ \\
\hline$\omega_{\max }$ & 26.45 & $\mathrm{rad} / \mathrm{s}$ \\
\hline
\end{tabular}

In Figure 2, the A point stands for the maximum force safety margin. If the penetration exceeds the point A then the turbine's blades start to brake. When the penetration value reaches nearly $28 \mathrm{kN}$ (point D), the turbine's blades were destroyed. Therefore, to protect the turbine, we put $\mathrm{c}$ as the primary safety margin which has penetration value of $2.5 \mathrm{kN}$. B means the secondary safety margin that $4 \mathrm{kN}$ is penetrated. For secondary safety margin, the angular velocity is $25 \mathrm{rad} / \mathrm{s}$ and angular velocity for primary safety margin is 20rad/s. Hence, for the simulation purpose, we set the primary safety margin angular velocity $\omega_{\text {lim }}$ as follows:

$$
\omega_{\text {lim }}=20 \mathrm{rad} / \mathrm{s} \text {. }
$$

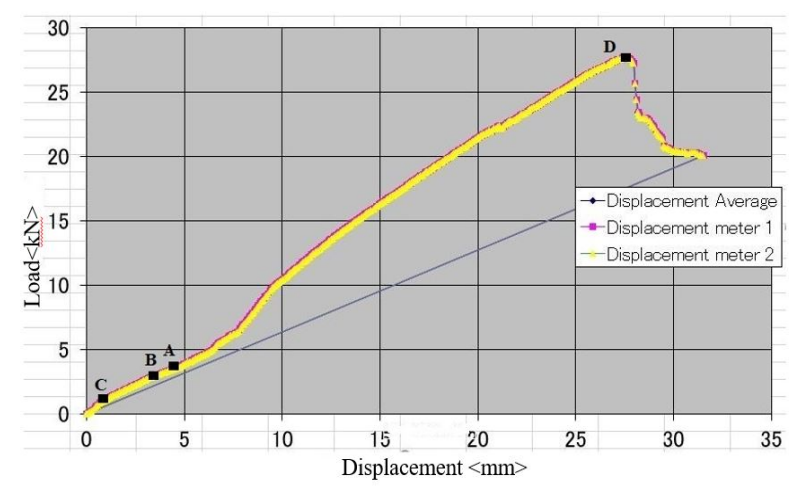

Figure 2. Blade destruction chart

\section{Structure of the system}

It is necessary to consider the electrical and mechanical aspect of the proposed system structure. For the mechanical section, we consider the brake system controlling structure. Here, the emergency rotation control eddy current brake system and MPPT control eddy current brake works independently which is illustrated in Figure 3. They always control the reference value of the angular velocity $\omega_{\text {ref }}$ and the angular velocity output $\omega$. When the controller receives the angular velocity of the turbine, controller will send its signal to two servo motors which are operates as emergency rotation control and MPPT control unit to place the magnets nearby the copper plates to control the rotation.

When the wind turbine rotates, the signal controller will receive the angular velocity measurement and it will send the signals to the emergency rotation control eddy current brake and MPPT control eddy current brake. According to the current rotation situation, above mentioned two brake systems will control the $f_{\text {emergency }(\omega)}$ which corresponds to emergency rotation control eddy current brake and $f_{M P P T(\omega)}$. Here, $f_{M P P T(\omega)}$ corresponds to MPPT control eddy current brake. This process is illustrated in Figure 4.

Figure 5, shows the entire block diagram of the small-scaled wind turbine system for realization in hardware. Here, $1 / s$ symbol represent the integrator symbol. For this system, the generator is considered as DC generator. Figure 6, displays the equivalent circuit of DC generator including the protection diode, load and battery.

Regarding the electrical aspect of the proposed system, important conditions are explained as follows. When the battery charge becomes low, the additional current from the generator will charge the battery. In the other hand, if the generator unable to supply demanded current, then battery will supply the required current to the load. If the battery is full and the required power is supplied to the load, then the turbine rotation is reduced using the eddy current brake system. 


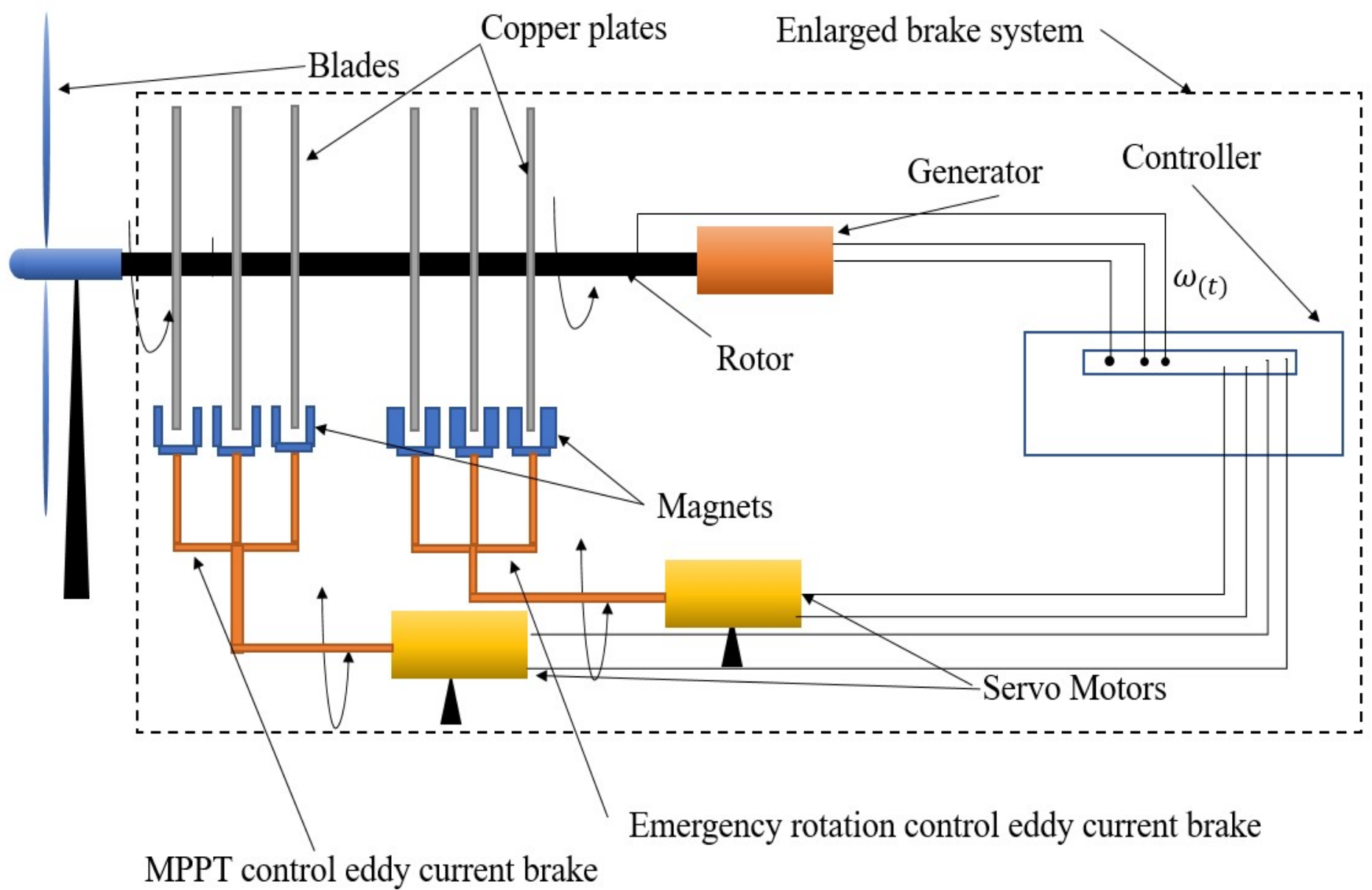

Brake system

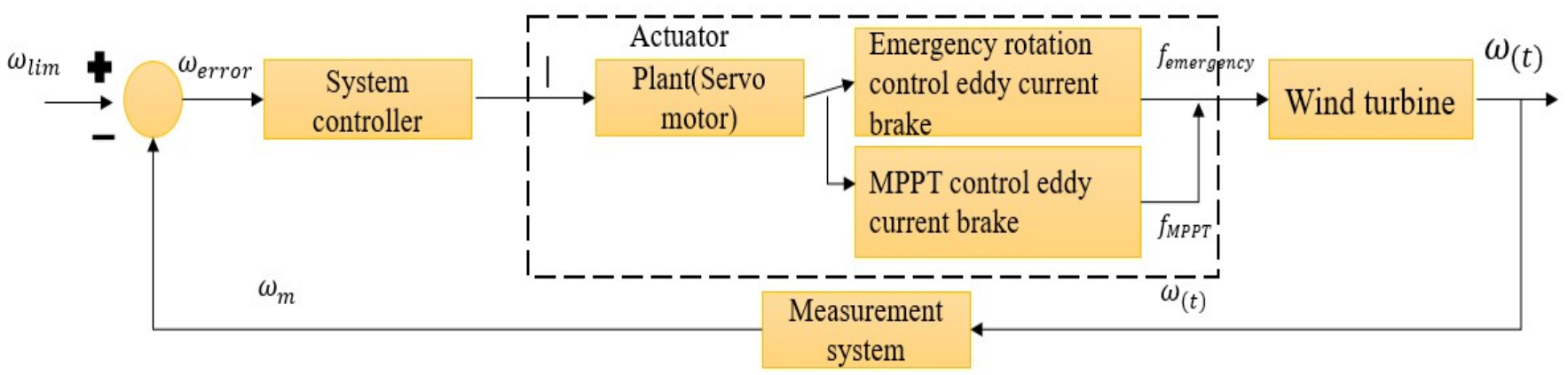

Figure 4. Control diagram 

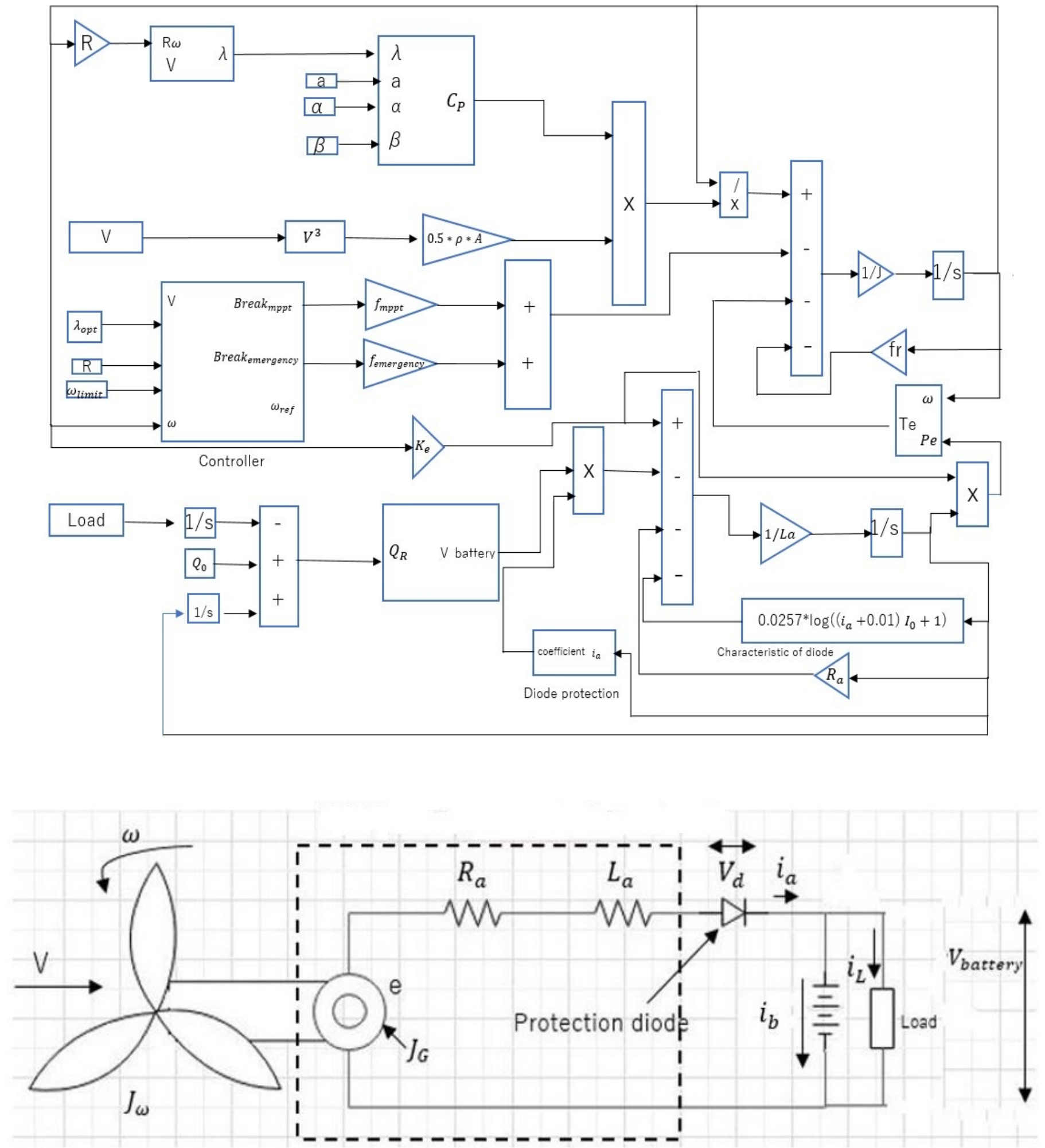

Figure 6. DC generator equivalent circuit diagram

Electromagnetic brake systems can be seen in modern world applications such as Maglev train brake system, gym instruments, and elevators, etc. Unlike the non-contactless braking operation, eddy current brake system can be considered as an efficient brake system [12].

www.astesj.com
Here, let us describe the eddy break system specifically. When the rotor shaft rotates in $\omega$ angular velocity, the magnetic flux between the two magnets are changing due to the interaction with the copper plate. Due to this magnetic flux change, eddy current $i_{\text {eddy }}$ will induce on the copper plate according to the faraday law of induction [13]. Due to the induced current, there will be 
opposing force or in the rotational case the torque generate against the rotation. This torque will act as the eddy current brake torque. In Figure $7, q_{m}$ means the magnitude of magnetic charge on magnetic poles and $q_{c}$ means magnitude of induced magnetic charge on copper plate.

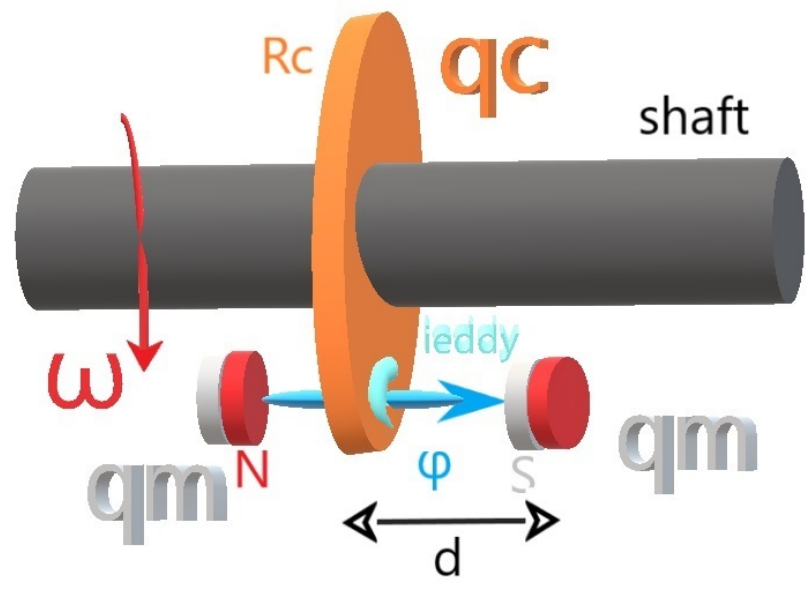

Figure 7. Eddy current brake

$$
\varepsilon=-\frac{d \varphi}{d t}
$$

where, $\varepsilon$ stands for electromotive force and $\varphi$ for magnetic flux.

Here, $R_{C}$ is the resistance of the copper plate and $I_{e d d y}$ is the induced eddy current on the copper plate. The relation with the $R_{C}$ and $I_{e d d y}$ is shown in (3), which is based on the ohm's law,

$$
\varepsilon=R_{c} I_{e d d y}
$$

From above equations, we can write down the eddy current as follows.

$$
I_{e d d y}=-\frac{1}{R c} \frac{d \varphi}{d t}
$$

Due to occurrence of above current, the break system is activated. Next section describes the dynamics of whole system.

\section{Mathematical modeling of the system}

This section introduces the mathematical modeling of the entire system. Therefore, it is important to consider the dynamics representation of mechanical and electrical part of the proposed system. The parameters were used for the mechanical section is displayed in table 2 and the electrical section is displayed in table 3 along with combined electrical and mechanical equations.

Equation (5) displays the summation of the inertia moments of the wind turbine and blades

$$
J=J_{\omega}+J_{G}
$$

The conventional mechanical and electrical dynamics of the system displayed in (6)

\begin{tabular}{|c|c|}
\hline Symbol & Name \\
\hline$J_{\omega}$ & Inertia moment of the blade \\
\hline$J_{G}$ & Inertia moment of the generator \\
\hline$\omega$ & Angular Velocity \\
\hline$\rho$ & Density of atmosphere \\
\hline$A$ & Area swept by blade \\
\hline$R$ & Length of blade \\
\hline$V_{(t)}$ & Speed of wind \\
\hline$f_{r}$ & Axis friction factor \\
\hline$\mu$ & Permeability \\
\hline$q_{m}$ & $\begin{array}{l}\text { Magnitude of the magnetic field of the } \\
\text { magnet }\end{array}$ \\
\hline$q_{c}$ & $\begin{array}{l}\text { Magnitude of the magnetic field of the } \\
\text { copper plate }\end{array}$ \\
\hline$d$ & Distance between copper plate and magnet \\
\hline$a_{a d j}$ & Decision functional adjustment \\
\hline$\omega_{\text {ref }}$ & Reference value of angular velocity \\
\hline$\omega_{\text {lim }}$ & Allowed maximum angular velocity \\
\hline$\omega_{\text {stall }}$ & Stall controlled angular velocity \\
\hline$I_{e d d y}$ & Induced eddy current \\
\hline$C_{P}$ & Power coefficient \\
\hline$C_{t}$ & Torque coefficient \\
\hline$k$ & Boltzmann's constant \\
\hline$f_{M P P T}$ & $\begin{array}{l}\text { Induced eddy current brake torque for MPPT } \\
\text { control }\end{array}$ \\
\hline$f_{\text {em }}$ & $\begin{array}{l}\text { Induced eddy current brake torque for } \\
\text { emergency brake }\end{array}$ \\
\hline
\end{tabular}

$$
J \frac{d \omega(t)}{d t}=\frac{1}{2} C_{T} \rho A R V_{(t)}^{2}-f_{r} \omega_{(t)}-T_{e}
$$

Table 2: Mechanical Parameters

This formula stands for controlling the brake plate rotation in a contact manner. However, in [8] we have proposed for contactless break system that is shown as follows.

$$
J \frac{d \omega(t)}{d t}=\frac{1}{2} C_{T} \rho A R V_{(t)}^{2}-f_{r} \omega_{(t)}-f_{m} f\left(\omega_{(t)}\right)-T_{e}
$$

where, $f m$ is the eddy current brake torque in following equation and $f($.$) is the decision function.$

$$
f_{m}=\mu \frac{2 q_{m} q_{c}}{4 \pi d^{2}}
$$

Here, $\mu$ stands for permeability of the space. $q_{m}$ and $q_{c}$ stands for magnitude of the magnetic field of the magnet and copper plate respectively. This formula is based on gilbert model magnetic force [14].

Next, we are going to model the electrical part of the system. In the following table the parameters are described.

Generated power is displayed in (8).

$$
P_{e}=\varepsilon i_{a}
$$

Electrical torque of the generator displayed in (9)

$$
T_{e}=\frac{P_{e}}{\omega}
$$

where, $\mathrm{e}_{a}$ stands for induced voltage and $\mathrm{i}_{a}$ for armature current. Equation (10) displays the battery electrical charge dynamics

$$
Q_{R}=Q_{0}+\int i_{a} d t-\int i_{L} d t
$$

As it is shown in above equation the remaining amount of battery capacity depends on the accumulation of consuming current and armature current that provided from turbine and battery 
initial capacity. Adversely, the current exchange among battery, turbine and loads can be retrieved by derivative of equation (10) which is

$$
i_{R}=i_{a}-i_{L}
$$

Table 3: Electrical Parameters

\begin{tabular}{|c|l|}
\hline Symbol & \multicolumn{1}{|c|}{ Name } \\
\hline$i_{a}$ & Output current of generator (armature current) \\
\hline$i_{b}$ & Charging current of the battery \\
\hline$i_{L}$ & Loads current \\
\hline$\varepsilon$ & Induced emf \\
\hline$V_{L}$ & Loads voltage \\
\hline$V_{\text {Battey }}$ & Battery Voltage \\
\hline$Q_{0}$ & Initial condition of the battery capacity \\
\hline$I_{0}$ & Saturated current \\
\hline$I_{d}$ & Flowing current \\
\hline$V_{d}$ & Voltage drop of diode \\
\hline$I_{S}$ & Saturated current \\
\hline$q$ & Electron charge \\
\hline$T$ & Temperature \\
\hline$K$ & Boltzmann constant \\
\hline
\end{tabular}

Therefore, whenever equation (11) becomes zero, the consuming and generating currents are balanced or if $i_{R}$ is greater than zero it is both charging mode to battery and providing currents to loads, simultaneously. Adversely, if $i_{R}$ is less than zero then the battery only provides the power to loads that is discharging mode.

From equivalent circuit of DC generator in Figure 6, the electrical dynamics of the system is obtained as follows.

$$
\varepsilon-R_{a} i_{a}-L \frac{d i_{a}}{d t}-V_{d}=V_{L}
$$

The purpose of setting diode in the output terminal of dc generator is to avoid being motor mode for dc generator when there is no wind penetration since battery is connected to generator's terminal. Thus, diode characteristic should be considered as well. The drop voltage of diode is shown in following equation.

$$
V_{d}=\frac{K T}{q} \ln \left(\frac{I_{d}}{I_{s}}+1\right)
$$

Where, $I_{d}$ corresponds to armature currents as following expression (14).

$$
I_{d}=I_{s}\left(e^{\frac{q V_{d}}{K T}}-1\right)
$$

Next, the induced electromotive force (emf) of the generator is displayed in (15).

$$
\varepsilon=K_{e} \omega
$$

Here, $\mathrm{K}_{\mathrm{e}}$ stands for Induced emf constant.

Up to here, the electrical model were described. From next equation the mechanical parts including the break terms are expressed.

The following equation shows the mechanical torque.

$$
T_{m}=\frac{P_{m}}{\omega}
$$

Below equation is based on the conventional break method, however, $C p$ is variable with respect to tip speed ratio.

$$
J \frac{d \omega(t)}{d t}=\frac{C_{P(\lambda)} \rho A R V_{(t)}^{2}}{2 \omega}-f_{r} \omega_{(t)}-f_{m} f\left(\omega_{(t)}\right)-T_{e}
$$

Then we can reform the above equation for proposed method by adding the eddy current brake for emergency brake and MPPT control that is shown as (18).

$$
J \frac{d \omega(t)}{d t}=\frac{C_{P}(\lambda) \rho A \mathrm{~V}_{(\mathrm{t})}^{2}}{2 \omega}-f_{r} \omega_{(t)}-T_{e}-\left(f_{m p} f_{M P P T(\omega)}+f_{\text {em }} f_{\text {emergency }(\omega)}\right)
$$

In above equation, $f_{M P P T}$ and $f_{\text {emergency }}$ has different values and $\mathrm{f}_{\mathrm{em}}$ value is larger than $f_{M P P T}$ since $f_{\text {emergency }}$ requires more braking force to control the over-rotation of the turbine than the force use to realize MPPT.

Equation 19 task is to work as a switch to keep the output power in a maximum state which means keep the angular velocity $\omega$ in the following condition: $\left(\omega<\omega_{\text {ref }}\right)$ that is in the MPPT operation status. However, if $\omega$ exceed $\omega_{\text {ref }}$ value $\left(\omega>\omega_{\text {ref }}\right)$, then the output power is not in a Maximum power state. Nevertheless, still the system is generating power since $\omega$ value isn't reached to $\omega_{\text {lim }}$ yet which is the safety margin of the wind turbine. If this situation going to happen then the emergency brake will start to reduce the $\omega$ value to keep the state as $\omega<\omega_{\text {lim }}$ condition. Therefore, equation 20 [15] task is to work as a switch to determine $\left(\omega<\omega_{\text {lim }}\right)$ condition.

$$
\begin{gathered}
f_{M P P T(\omega)}=\frac{1}{2}+\frac{1}{\pi} \tan ^{-1}\left(\alpha_{\text {adj }}\left(\omega-\omega_{\text {ref }}\right)\right) \\
f_{\text {emergency }(\omega)}=\frac{1}{2}+\frac{1}{\pi} \tan ^{-1}\left(\alpha_{\text {adj }}\left(\omega-\omega_{\text {lim }}\right)\right)
\end{gathered}
$$

The reference value of the angular velocity is shown in (21). Here the $\lambda_{\text {opt }}$ means the optimum value of tip speed ratio.

$$
\omega_{\text {ref }}=V \frac{\lambda_{\text {opt }}}{R}
$$

$\omega_{\text {ref }}$, value is a function of $\lambda_{\text {opt }}$ and $V$. Since this is a small wind turbine, $\lambda_{\text {opt }}$ value require small value to obtain $C_{P}^{\text {opt }}$ value. Due to the compatibility of small-scaled turbine, we designed the mathematical expression of the $C_{P}$ as mentioned below in (22) and $\mathrm{C}_{\mathrm{P}}-\lambda$ relationship shown in Figure 8.

$$
C_{P}=-a(\lambda-\alpha)(\lambda-\beta)
$$

Where, the condition of coefficients is a $>0$ and $\beta>\alpha$.

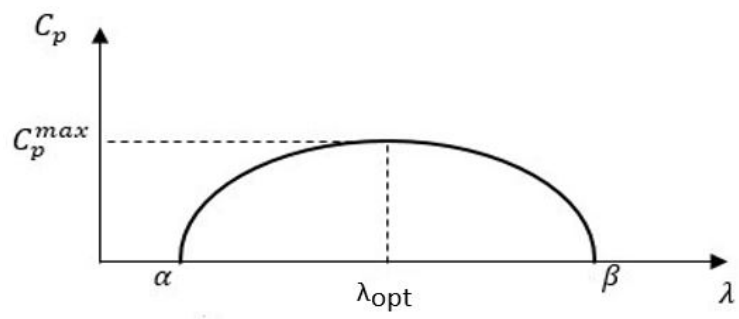

Figure $8 . \mathrm{C}_{\mathrm{P}}-\lambda$ curve

Optimum value of wind turbine power factor is shown in (23).

$$
C_{P}^{\max }=\frac{\alpha+\beta}{2}
$$


As it is shown in Figure 7 the output terminal of generator is connected to a battery and battery is connected to the loads in parallel. Therefore, in order to verify the battery voltage, we have designed a battery capacity charging in which the battery voltage can be obtained by the Equation (24) represents the characteristic of the accumulated consumed current.

$$
V_{\text {Battery }}=\frac{V_{\max }-V_{\min }}{0.5-\frac{1}{\pi} \tan ^{-1}(20 \times(-5))}\left(\frac{1}{2}+\frac{1}{\pi} \tan ^{-1}\left(1\left(Q_{R}-5\right)\right)\right)
$$

Notice that the load voltage and battery voltage is identical since as it has been mentioned they are connected in parallel.

\section{Simulation and results}

In this section, we conduct the simulation in two steps. First, we simulated the entire system for different average wind velocities from $7 \mathrm{~m} / \mathrm{s}, 14 \mathrm{~m} / \mathrm{s}, 21 \mathrm{~m} / \mathrm{s}$ and $28 \mathrm{~m} / \mathrm{s}$, respectively. Then plotted the stall control charts for above velocities. We did this step to analyze the wind turbines stall control behavior for different wind velocities. Afterwards, we plotted the Mechanical power (Pm) and power coefficient of the system for different conditions. For the second step, we simulated the entire system for calm and storm days wind conditions for one day and analyzed the behavior of outputs of the system.

\subsection{Simulation conditions}

This section explains the conditions of the simulation and system we used in order to conduct the simulation. The load data for the system is applied using real mango greenhouse system in Okinawa [16]. Load pattern is displayed in Figure 9. This load consists of Light emitting diode (LED) lights, Compact Fluorescent Light (CFL) lights, Electrical Fans. According to the Figure 9 the highest load value is $12.8 \mathrm{~A}$. Here, the sample time for the simulation is $0.01 \mathrm{~s}$. MATLAB/Simulink software platform is used for the simulation. For the simplicity, simulation time is set to be 100 s from Figure 10 to Figure 21. From Figure 22 to Figure 33 , simulation time is one day long. Values of the parameters for simulation are displayed specifically in Table 4.

Table 4: Parameters of simulation

\begin{tabular}{|c|c|c|}
\hline Symbol & Value & Unit \\
\hline$\omega$ & Variable & rads \\
\hline$\rho$ & 1.225 & $\mathrm{~kg} \cdot \mathrm{m}^{3}$ \\
\hline$A$ & 19.625 & $\mathrm{~m}^{2}$ \\
\hline$R$ & 2.5 & $\mathrm{~m}$ \\
\hline$V_{(t)}$ & Variable & $\mathrm{ms} \mathrm{s}^{-1}$ \\
\hline$f_{r}$ & 0.1 & $\mathrm{~kg} \cdot \mathrm{m}^{2} s^{-1}$ \\
\hline$f_{\text {mppt }}$ & 2200 & $\mathrm{~kg} \cdot \mathrm{m} s^{-2}$ \\
\hline$f_{\text {emergency }}$ & 5800 & $\mathrm{~kg} \cdot \mathrm{m} s^{-2}$ \\
\hline$\mu$ & $4 \pi 10^{-7}$ & $\mathrm{~T} \cdot \mathrm{m} \cdot A^{-1}$ \\
\hline$q_{m}$ & $62.5^{*} 10^{9}$ & $\mathrm{~A} \cdot \mathrm{m}$ \\
\hline$q_{c}$ & $0.1^{*} 10^{-4}$ & $\mathrm{~A} \cdot \mathrm{m}$ \\
\hline$d$ & 0.05 & $\mathrm{~m}$ \\
\hline
\end{tabular}

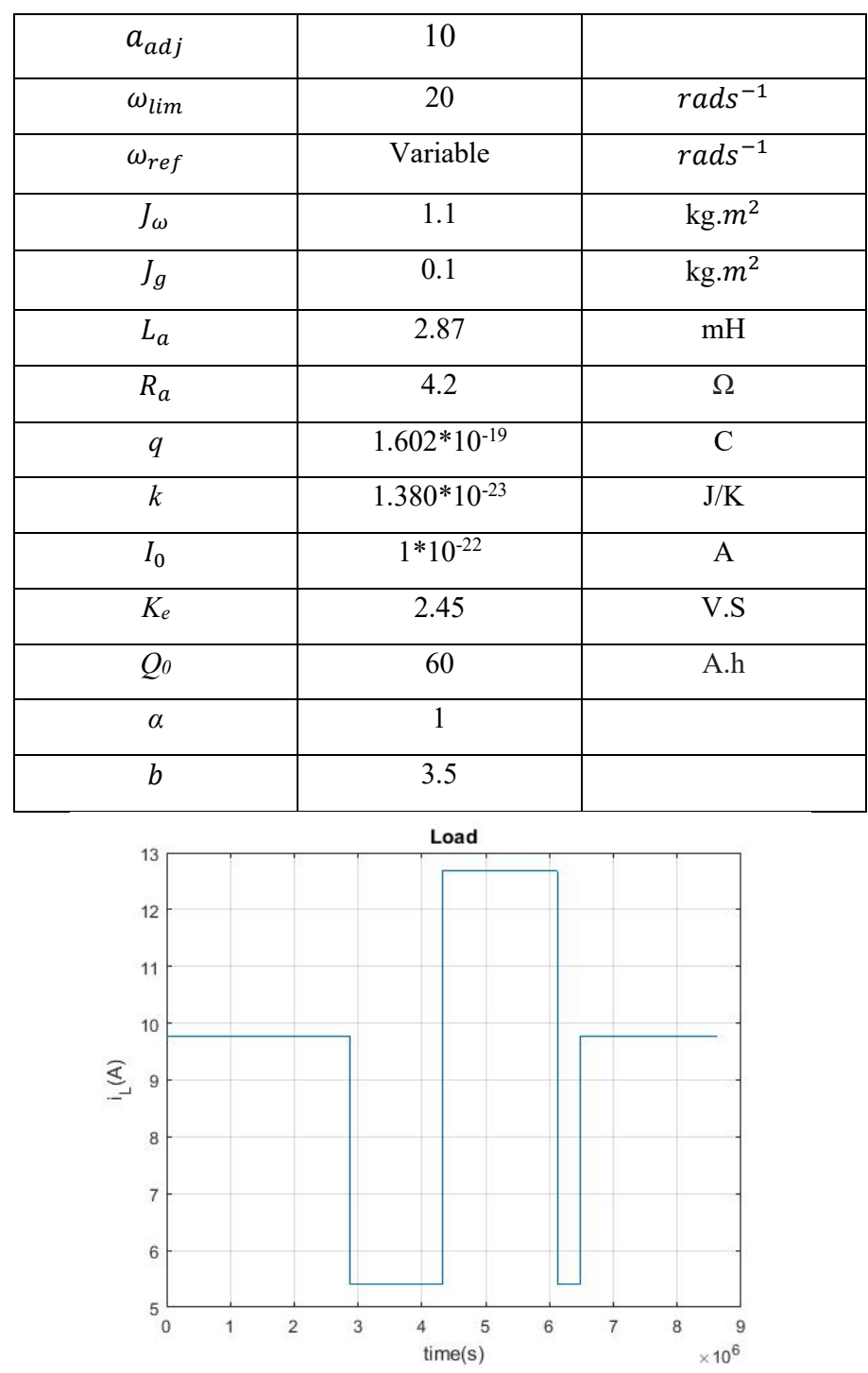

Figure 9. Load

\subsection{Results}

From figure 10 to figure 13 , they display the stall control chart for $7 \mathrm{~m} / \mathrm{s}, 14 \mathrm{~m} / \mathrm{s}, 21 \mathrm{~m} / \mathrm{s}, 28 \mathrm{~m} / \mathrm{s}$, respectively.

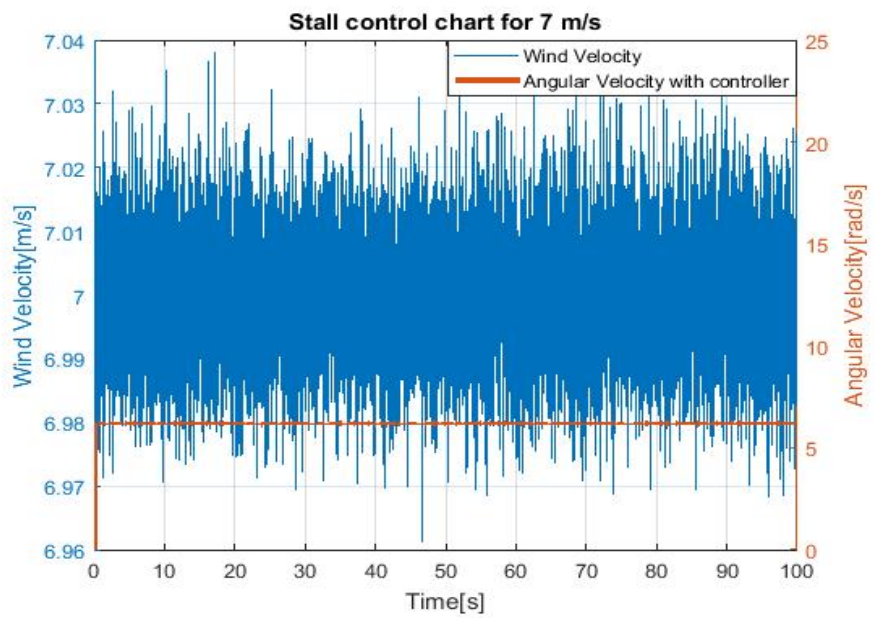

Figure 10. Stall control chart for $7 \mathrm{~m} / \mathrm{s}$ 


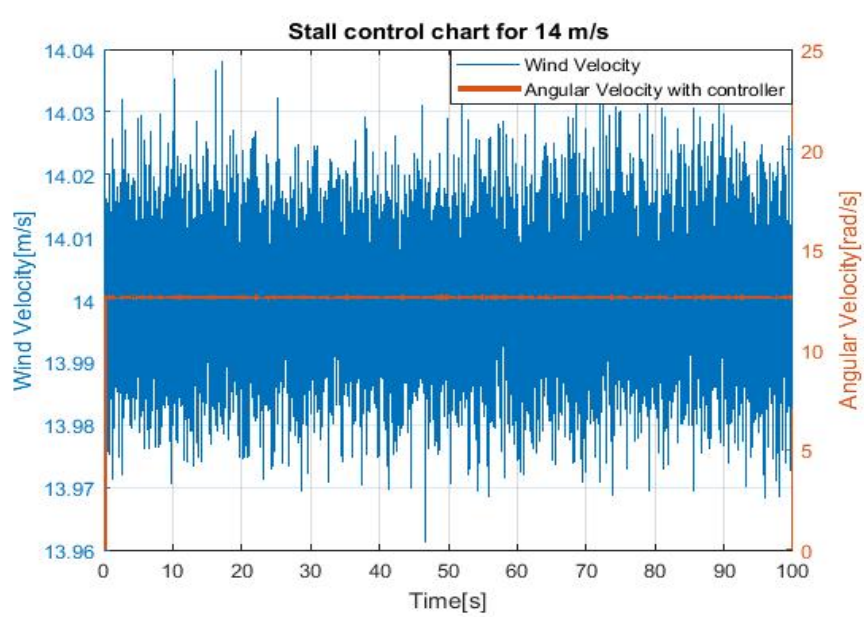

Figure 11. Stall control chart for $14 \mathrm{~m} / \mathrm{s}$

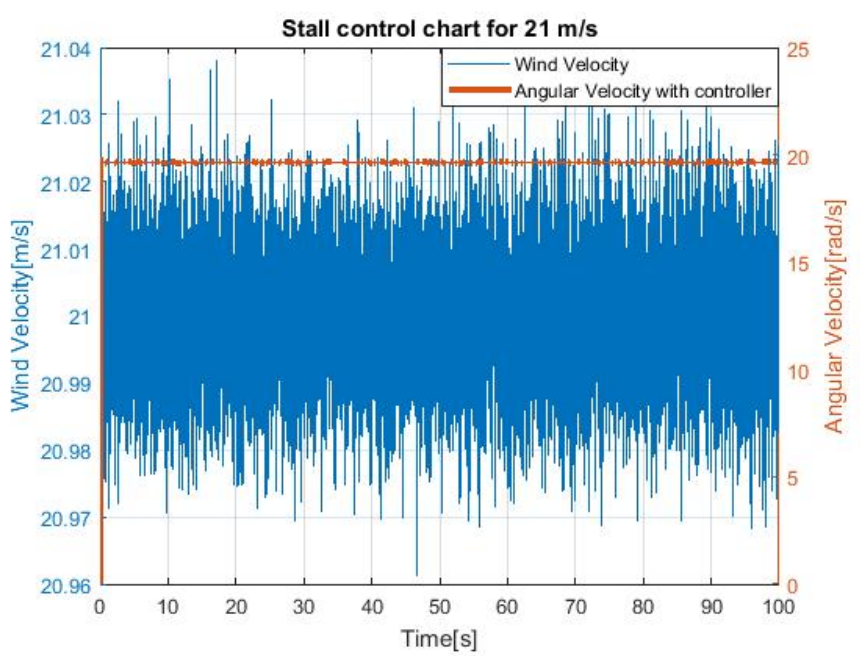

Figure 12. Stall control chart for $21 \mathrm{~m} / \mathrm{s}$

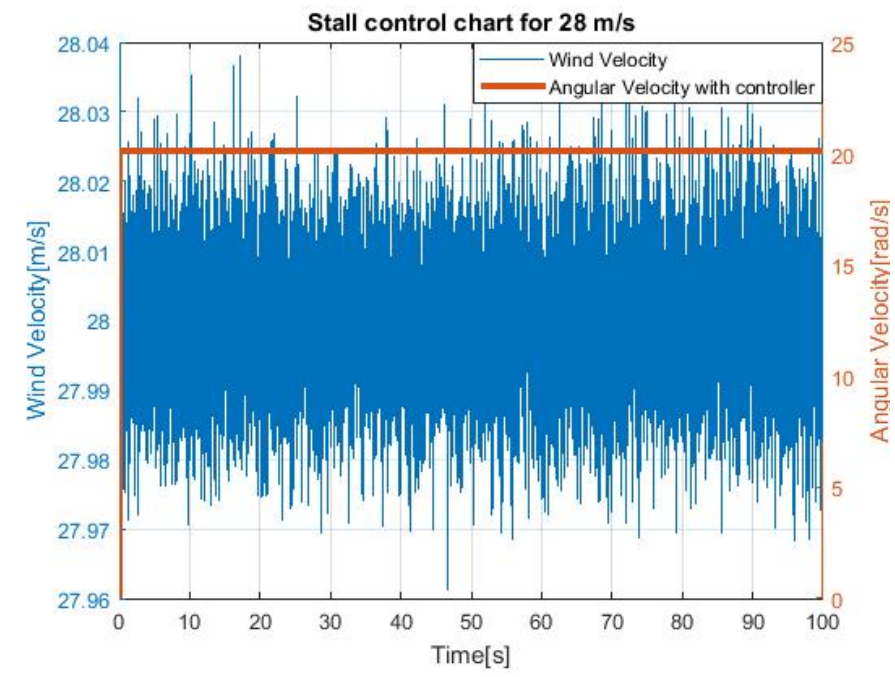

Figure 13. Stall control chart for $28 \mathrm{~m} / \mathrm{s}$

According to above stall control figures, the wind turbine angular velocity emergency control is valid up to $28 \mathrm{~m} / \mathrm{s}$ velocity. Therefore, the eddy current brake system can control the overrotation of the wind turbine up to $28 \mathrm{~m} / \mathrm{s}$.
Table 5 shows the $\omega_{\text {ref }}$ which is optimal angular velocity to realize the maximum power operation and $\omega_{\text {stall }}$ is the actual output of angular velocity.

Table 5: $\omega_{\text {ref }}$ and $\omega_{\text {stall }}$ comparison

\begin{tabular}{|l|l|l|}
\hline $\begin{array}{l}\text { Input } \\
\text { velocity }\end{array}$ & \multicolumn{1}{|c|}{$\omega_{\text {ref }}$} & $\omega_{\text {stall }}$ \\
\hline 7 & 6.299 & 6.1849 \\
\hline 14 & 12.5999 & 12.5994 \\
\hline 21 & 18.8999 & 19.6377 \\
\hline 28 & 25.199 & 20.094 \\
\hline
\end{tabular}

As it is obvious in the above table, the output angular velocity for input wind is lower than the optimal angular velocity since in high wind penetration emergency break is activated. Specifically, comparing to the $\omega_{\text {stall }}, \omega_{\text {ref }}$ value is becoming lower when wind velocity increase. That means when the input wind velocity is $28 \mathrm{~m} / \mathrm{s}$ the $\omega_{\text {ref }}$ value is 25.199 the MPPT control is stopped because $\omega>\omega_{\text {ref. }}$. However wind turbine is still operating using the emergency eddy current brake since $\omega_{\text {stall }}$ is nearly the value of $\omega_{\text {lim }}$. Next, from Figure 14 to Figure 17, The instantaneous angular velocity deviation $\Delta \omega=\omega_{\text {stall }}-\omega_{\text {ref }}$ show their behavior for $7 \mathrm{~m} / \mathrm{s}, 14 \mathrm{~m} / \mathrm{s}, 21 \mathrm{~m} / \mathrm{s}, 28 \mathrm{~m} / \mathrm{s}$ average wind velocities, respectively.

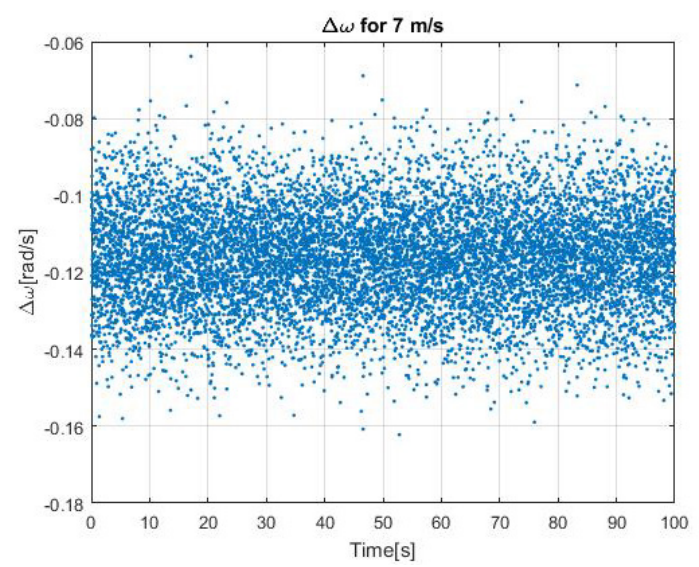

Figure 14. $\Delta \omega$ for $7 \mathrm{~m} / \mathrm{s}$

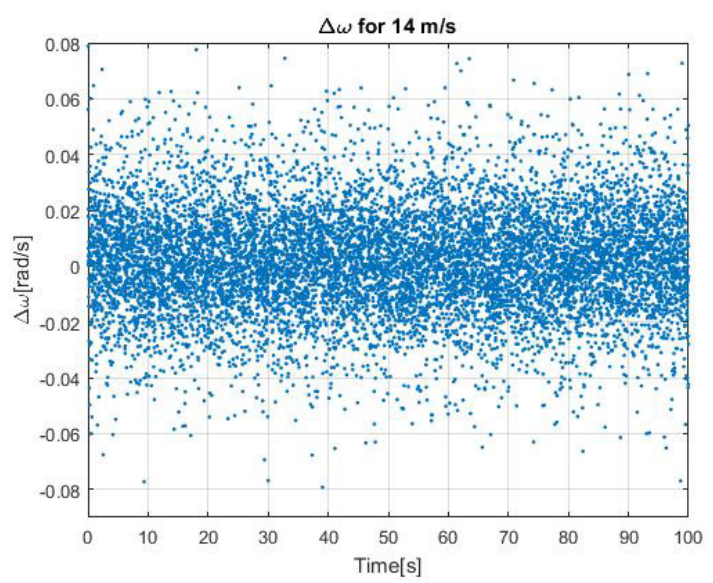

Figure $15 . \Delta \omega$ for $14 \mathrm{~m} / \mathrm{s}$ 


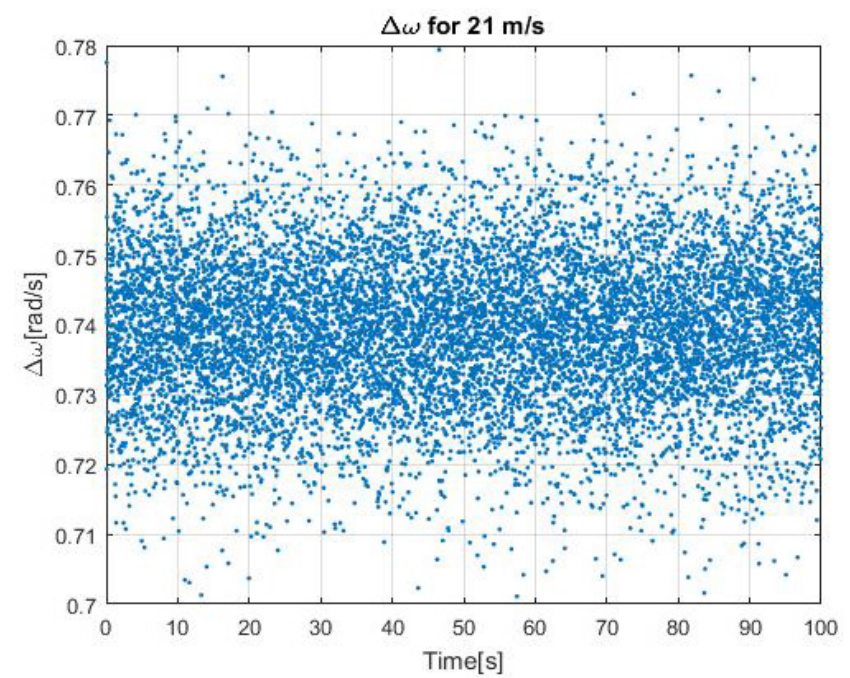

Figure 16. $\Delta \omega$ for $21 \mathrm{~m} / \mathrm{s}$

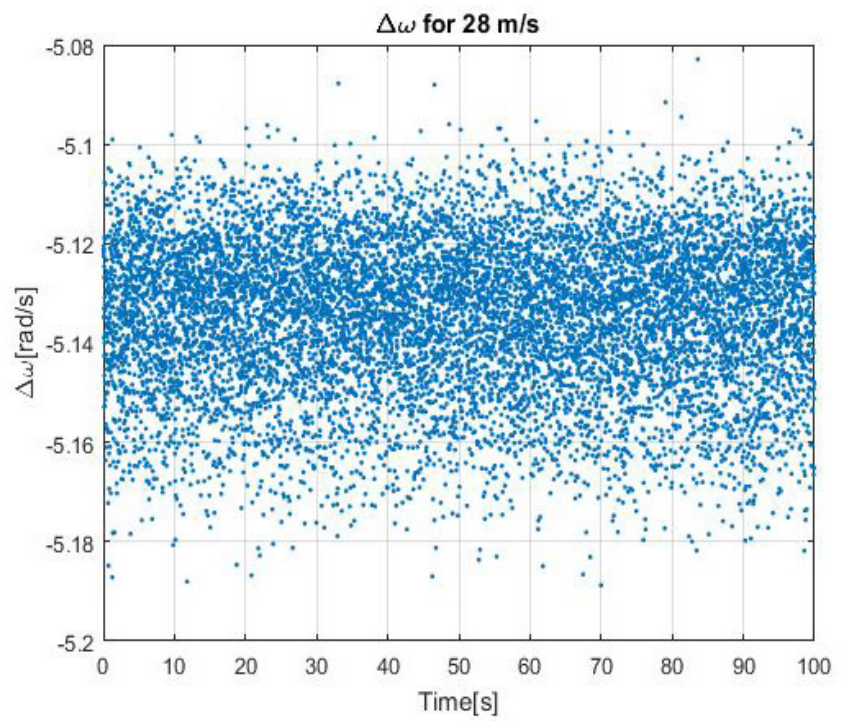

Figure 17. $\Delta \omega$ for $28 \mathrm{~m} / \mathrm{s}$

The mechanical power comparison with and without MPPT and emergency brake and $\mathrm{Cp}$ behavior comparison with and without the MPPT and emergency brake are shown from Figure 18 to Figure 21.

According to the Figure 18, when the average wind velocity is $7 \mathrm{~m} / \mathrm{s}$ the mechanical power with the MPPT and emergency brake has higher value comparing to without the MPPT and emergency brake. As well, for $\mathrm{Cp}$, when the MPPT and emergency brake is triggered it contains higher value. But, when $\mathrm{Cp}$ is without the control of MPPT and emergency brake, the value is low.

In Figure 19, Figure 20 and Figure 21 which are correspond to average wind velocity of $14 \mathrm{~m} / \mathrm{s}, 21 \mathrm{~m} / \mathrm{s}$ and $28 \mathrm{~m} / \mathrm{s}$, they have the same comparison results as mentioned in above for $7 \mathrm{~m} / \mathrm{s}$. Therefore, it is obvious that when the system is under the controlled state for MPPT and over-rotation, the mechanical power of the wind turbine and the power factor $(\mathrm{Cp})$ have their maximum values.

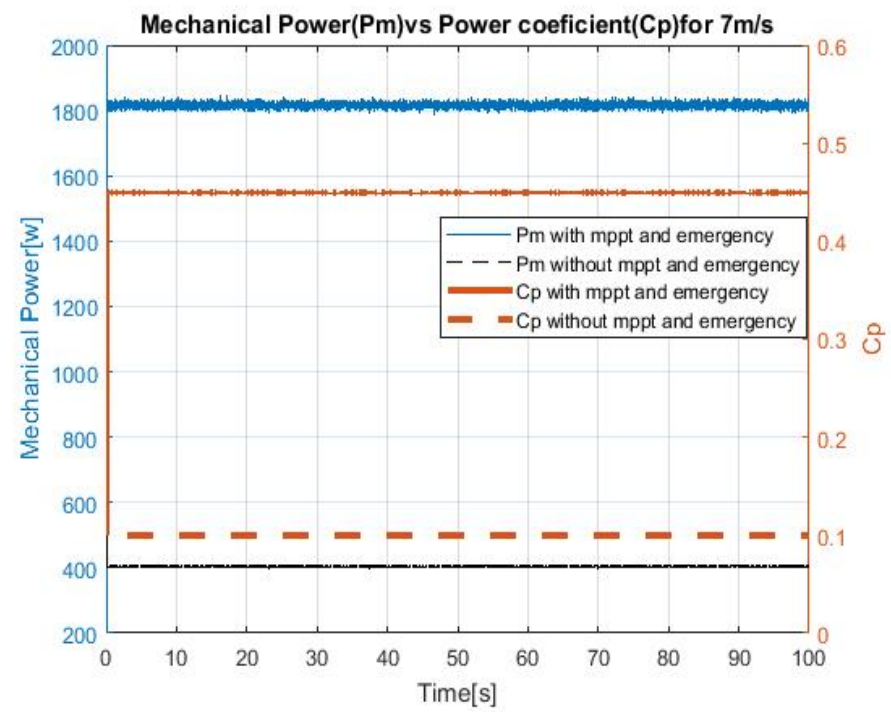

Figure 18. Pm vs $\mathrm{Cp}$ for $7 \mathrm{~m} / \mathrm{s}$

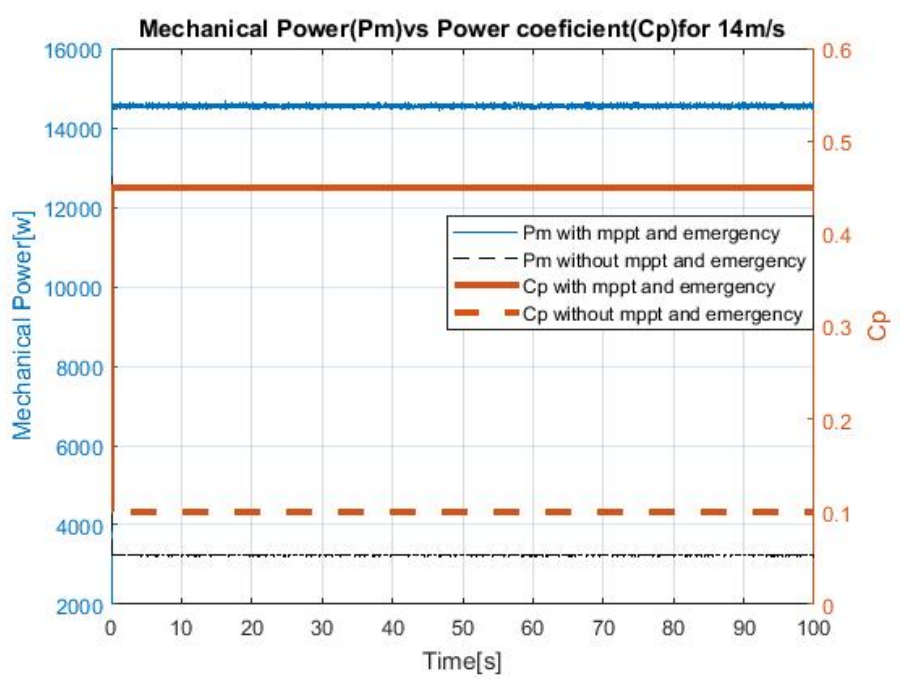

Figure 19. Pm vs $\mathrm{Cp}$ for $14 \mathrm{~m} / \mathrm{s}$

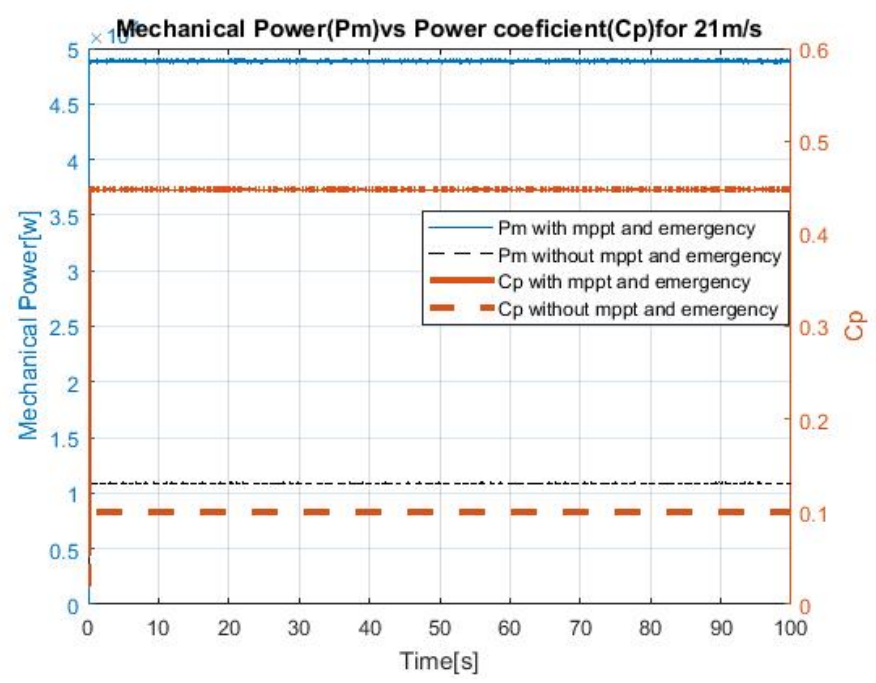

Figure 20. Pm vs $\mathrm{Cp}$ for $21 \mathrm{~m} / \mathrm{s}$ 


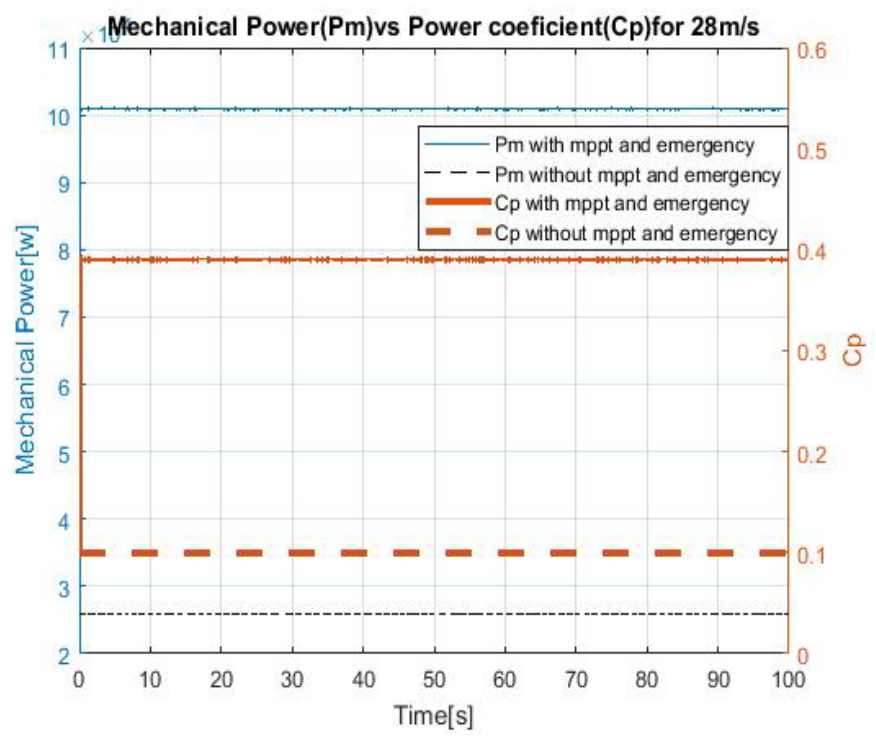

Figure 21. Pm vs Cp for $28 \mathrm{~m} / \mathrm{s}$

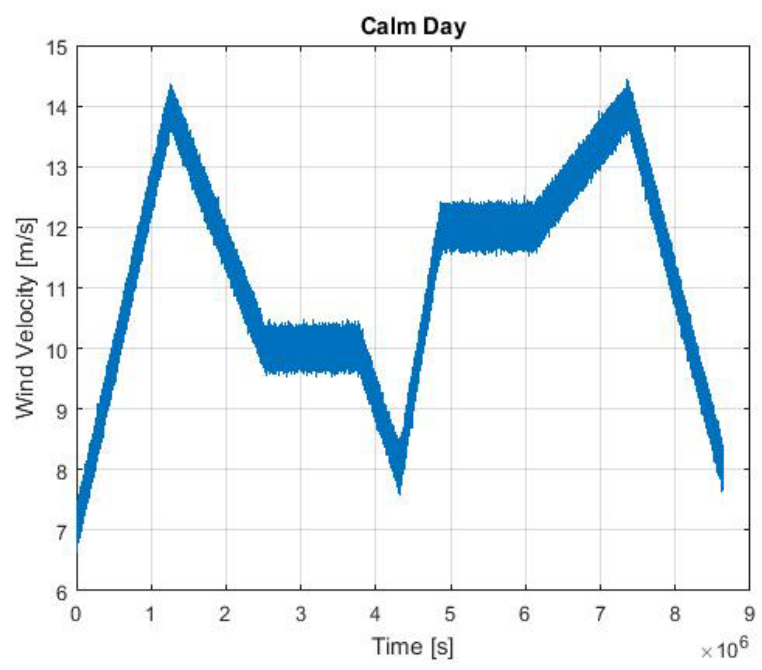

Figure 22. Calm day wind pattern

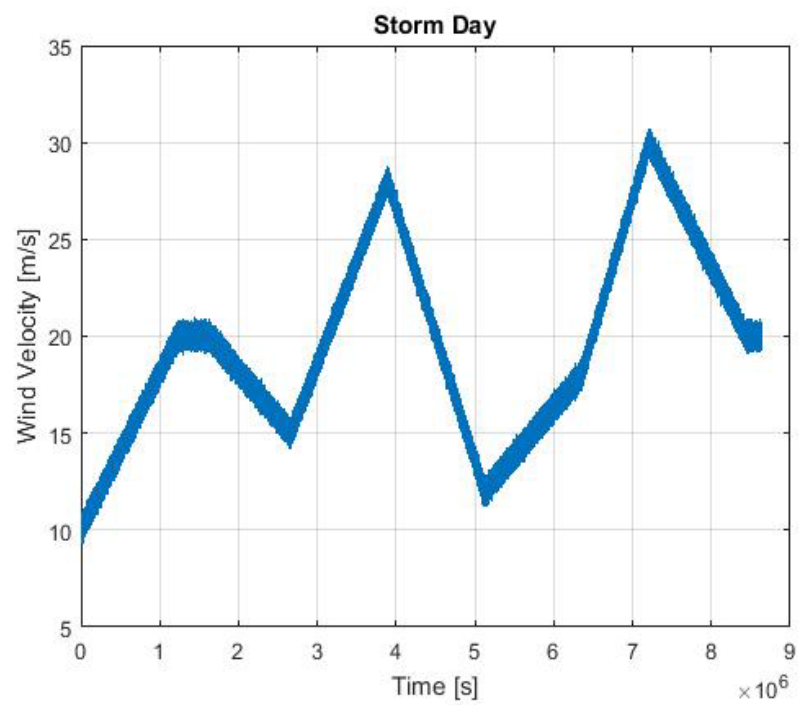

Figure 23. Storm day wind pattern
We have artificially created two wind patterns for the simulation process. First, we have done the simulation for calm day and then for the storm day condition. For calm day and storm day wind patterns are shown in Figure 22 and Figure 23. For the first phase of calm day the velocity gradually increases from $7 \mathrm{~m} / \mathrm{s}$ to $14 \mathrm{~m} / \mathrm{s}$. Afterward, it decreases gradually from $14 \mathrm{~m} / \mathrm{s}$ to $10 \mathrm{~m} / \mathrm{s}$. Then the $10 \mathrm{~m} / \mathrm{s}$ wind velocity maintain stable for few hours. Afterwards the velocity will decrease until $8 \mathrm{~m} / \mathrm{s}$. Then, it will increase from $8 \mathrm{~m} / \mathrm{s}$ to $12 \mathrm{~m} / \mathrm{s}$. Again, it will increase from $12 \mathrm{~m} / \mathrm{s}$ to $14 \mathrm{~m} / \mathrm{s}$ gradually. Finally, the velocity will decrease from $14 \mathrm{~m} / \mathrm{s}$ to $8 \mathrm{~m} / \mathrm{s}$. For calm day the highest wind speed is approximately $14.3 \mathrm{~m} / \mathrm{s}$ and storm day the highest wind speed is approximately $30 \mathrm{~m} / \mathrm{s}$. Lowest wind speed for calm day and storm day are $7 \mathrm{~m} / \mathrm{s}$ and $10 \mathrm{~m} / \mathrm{s}$.

Next, Figure 24 and Figure 25 shows the angular velocity deviation $\Delta \omega$ values which changes with respect to the wind condition. There are some peaks occurred according to the Figure 22. These peaks happen due to the emergency braking for sudden wind condition changes. Here, the $\Delta \omega$ is nearly zero means the wind turbine produces its maximum power.

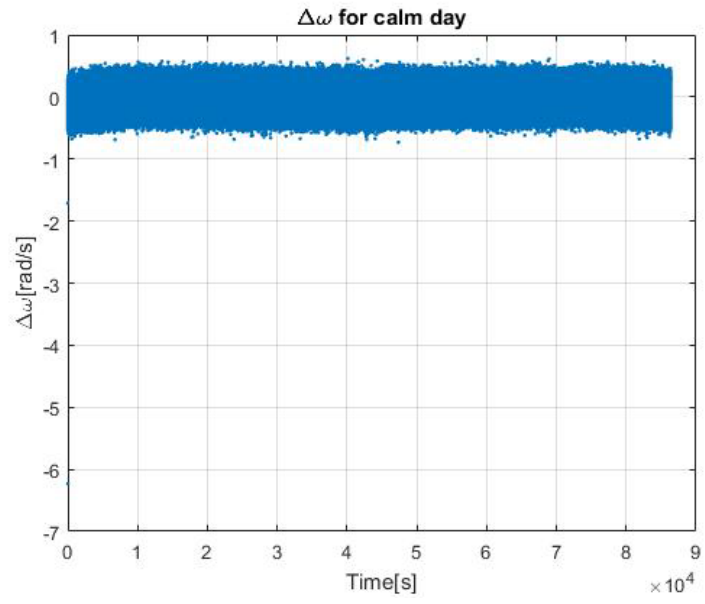

Figure 24. $\Delta \omega$ for calm day

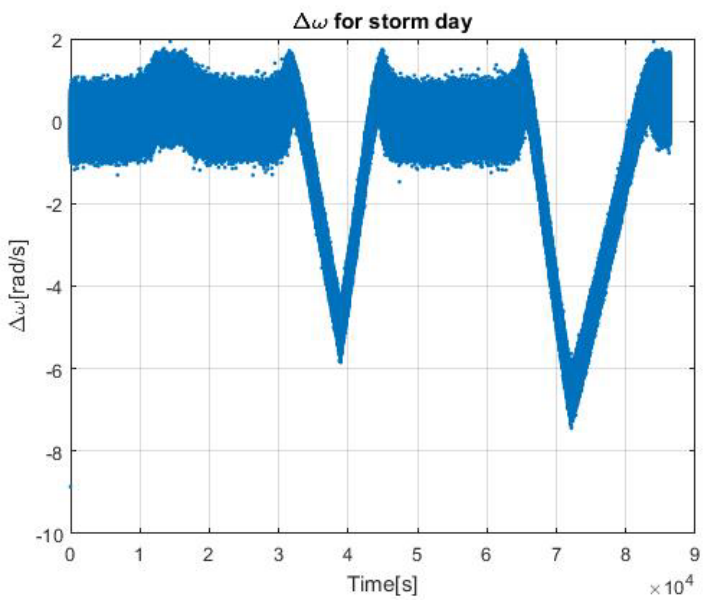

Figure 25. $\Delta \omega$ for storm day

In calm day, the angular velocity does not achieve to critical value which is $20 \mathrm{rad} / \mathrm{s}$. Nevertheless, according to angular velocity deviation in Figure 24, it is attempting to reach the angular velocity that operates at maximum power point. Same to Storm day, angular velocity tries to operate at its maximum power point. 
However, as it can be seen Figure 25, the deviation of angular velocity has negative two peaks for some determined period. Correspondingly, it is obvious in Figure 27 that during the peaks of angular velocity deviations the output of angular velocity is suppress by $20 \mathrm{rad} / \mathrm{s}$. Thus, the emergency brake is also activated in storm situation.

The angular velocity always kept under $\omega_{\text {lim }}=20$ for both calm day and storm day stall control patterns which are shown in Figure 26 and Figure 27.

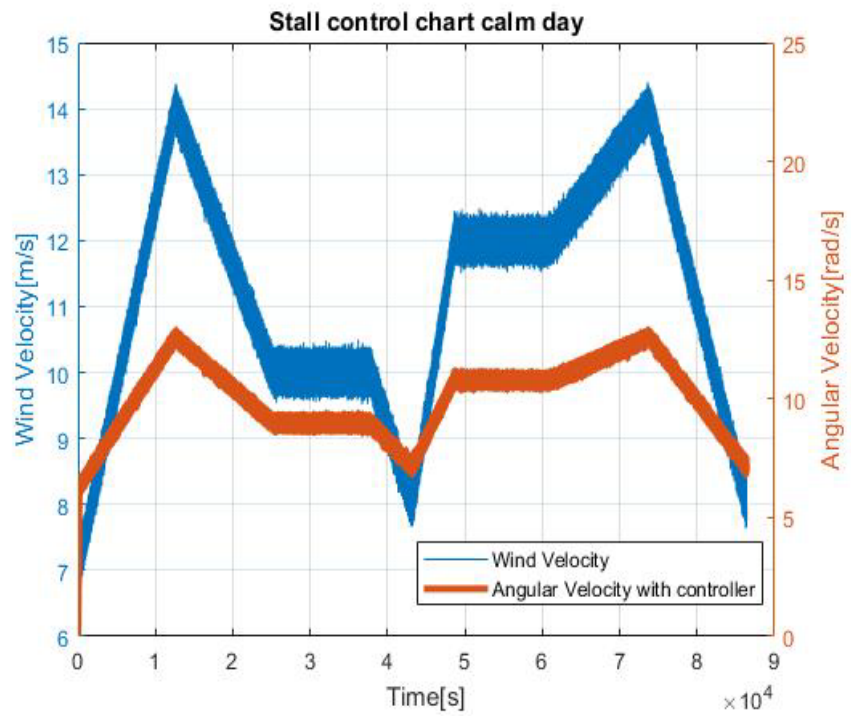

Figure 26. Stall control chart for calm day

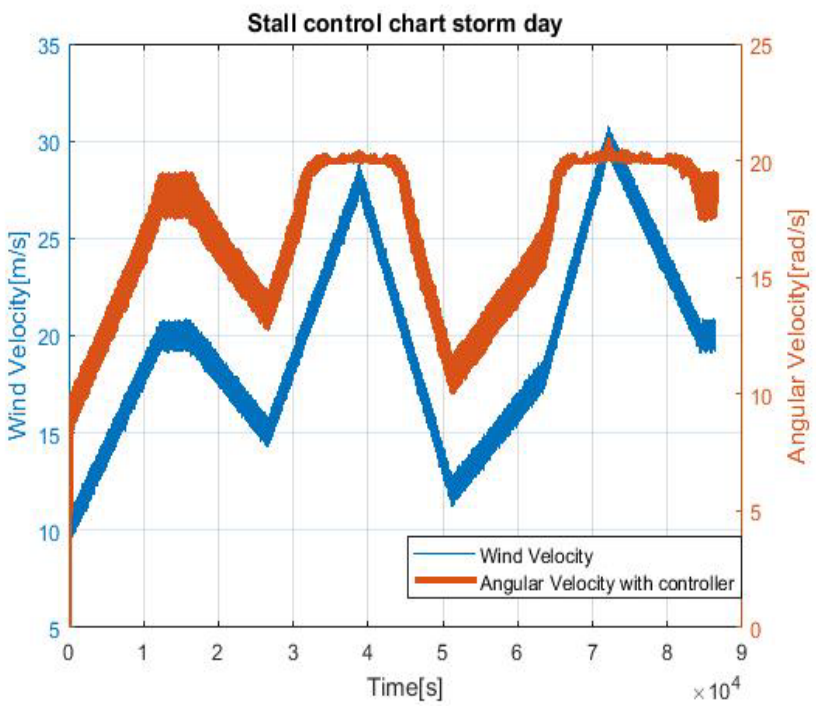

Figure 27. Stall control chart for storm day

Figure 28 and Figure 29 displays the Mechanical power (Pm), Electrical power $(\mathrm{Pe})$, Electrical torque (Te) for calm day and Pe, $\mathrm{Pm}, \mathrm{Te}, \mathrm{Tm}$ for storm day. According to those figures the Pe, Pm, $\mathrm{Te}, \mathrm{Tm}$ have higher values comparing to the calm day for emergency brake and MPPT brake activated state. Therefore, the small wind turbine is capable of generating high power even in a storm day.

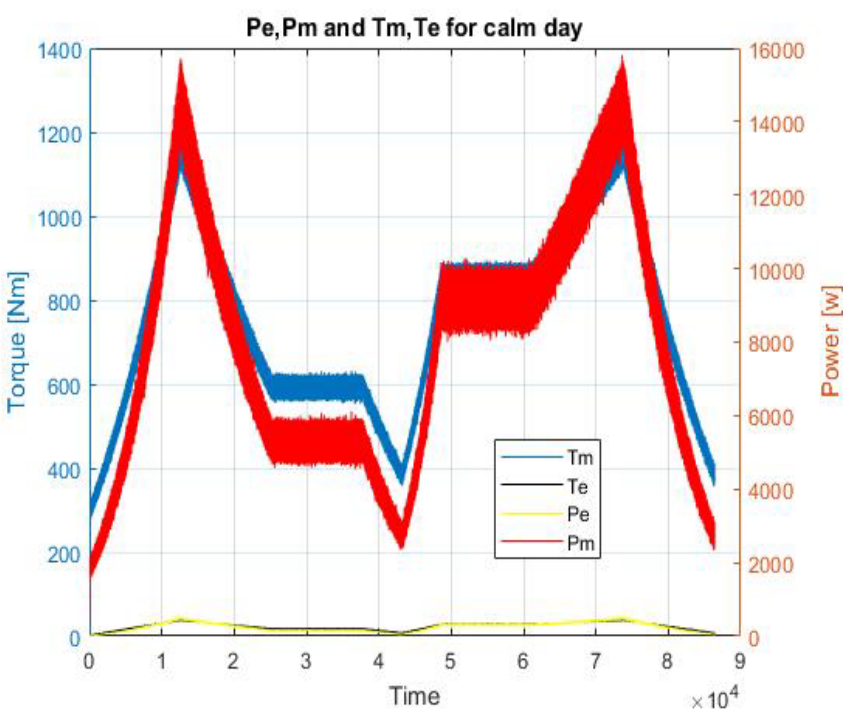

Figure 28. Pe,Pm, Tm and Te for calm day

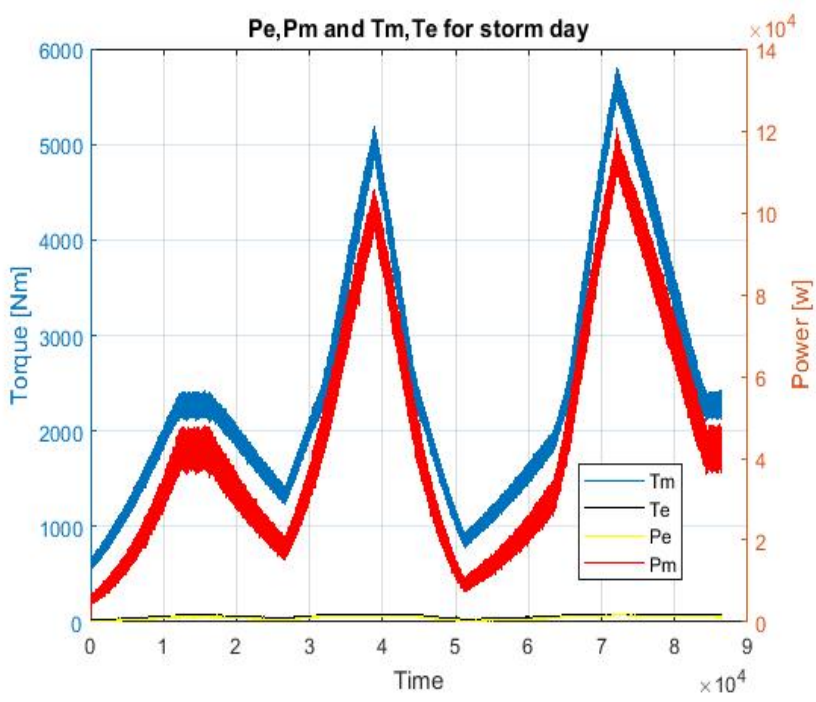

Figure 29. Pe,Pm, Tm and Te for storm day

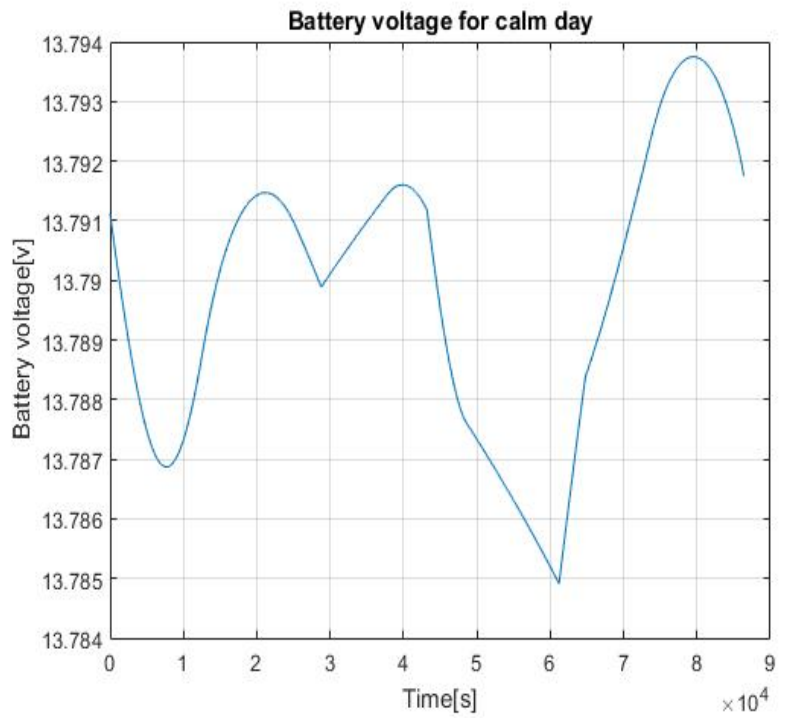

Figure 30. Battery voltage for calm day 
According to Figure 30 and Figure 31, the battery voltage for storm day has good performance comparing to the battery voltage for calm day. Thus, for both cases we can say it has sufficient amount of voltage.

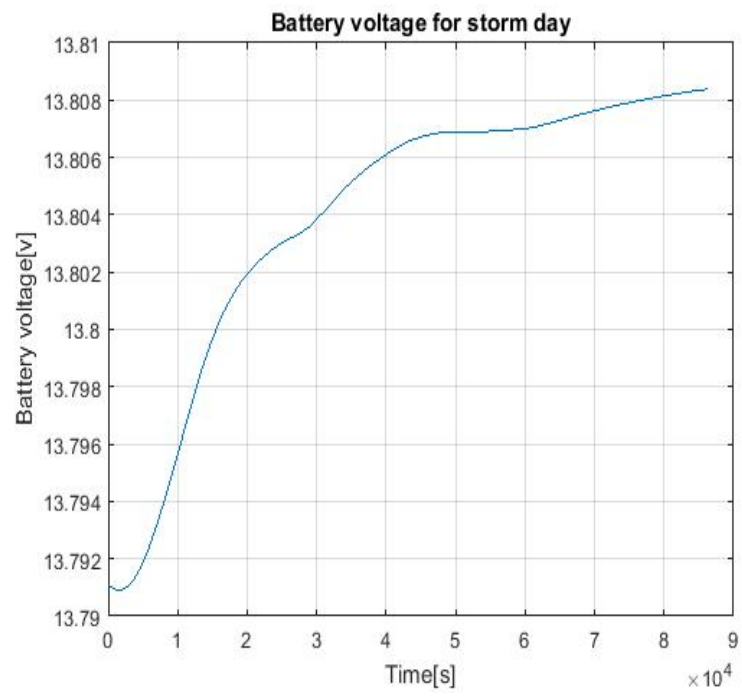

Figure 31. Battery voltage for storm day

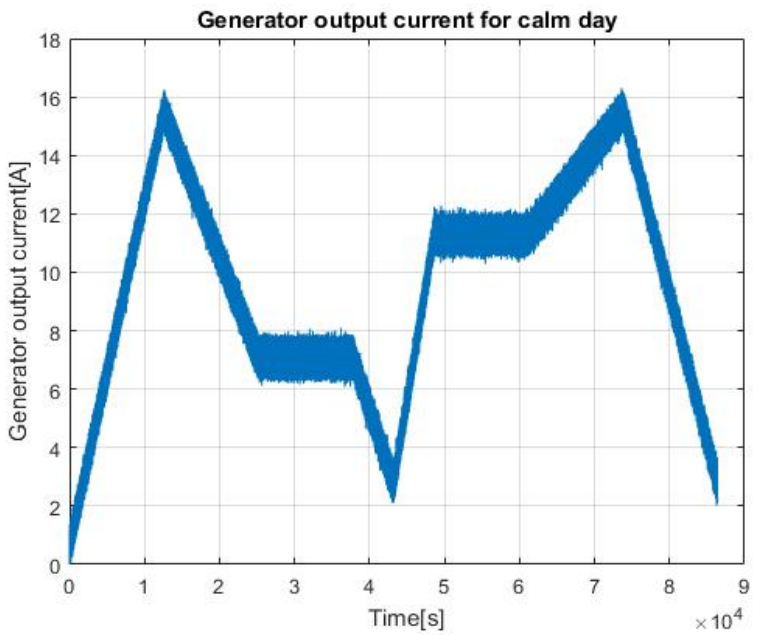

Figure 32. Generator output current for calm day

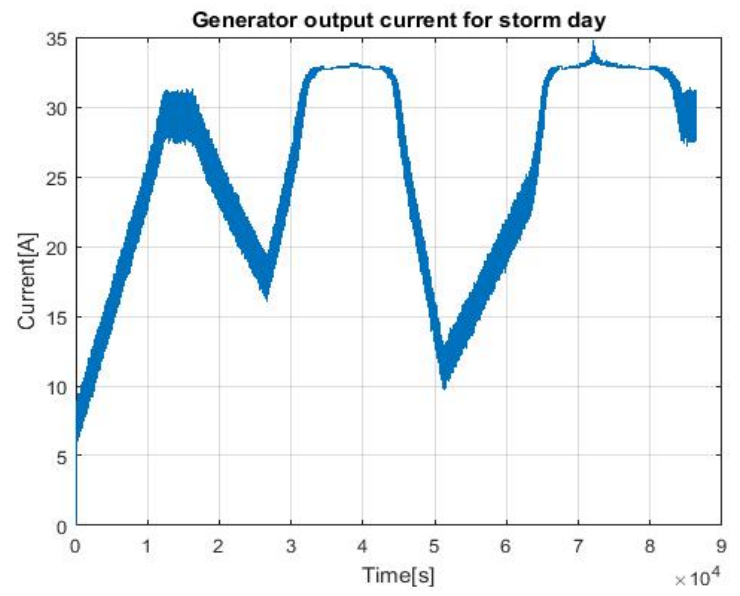

Figure 33. Generator output current for storm day
Figure 32 and Figure 33 shows the generator output current for calm day and storm day. For storm day, the generator output current has significant increase comparing to the clam day current in the MPPT and emergency brake-controlled condition. Nevertheless, even in calm day sufficient capacity of battery is maintained which is sustainable for providing the power to greenhouse environmental loads. Thus, we can conclude that efficiency of power extraction is improved with cooperative of the emergency operation.

\section{Conclusion}

We have conducted the simulation for different wind condition and analyzed the behavior of the system when the system is in control of MPPT and Eddy current brake conditions. Moreover, the analogical experiment for the small-scaled wind turbines to decide the maximum penetration value and maximum angular velocity the wind turbine blades can withhold was performed. Therefore, we can conclude that the behavior of the system is in controlled state by using above mentioned control methods. We believe the eddy current brake system can be implemented in a small-scaled wind turbine system for the purpose of MPPT and control the over-rotation by strong wind. As future works, we will add pitch control for establish the system more robust. Also, the real system will be implemented.

\section{Conflict of Interest}

The authors declare no conflict of interest.

\section{Reference}

[1] J.F Manwell, J.G. Mcgowan, A.L. Rogers, Wind Energy Explained, John Wiley and Sons, 2009.

[2] F. Asharif, S. Tamaki, T. Nagado, T. Nagata M.R. Asharif, "Analysis of nonlinear adaptive friction and pitch angle control of small-scaled wind turbine system," Future Generation Information Technology FGIT 2011, Control and Automation CA, Springer-Verlag, Lecture Note: Communication in Computer and Information Science, 26-35, December 2011. https://doi.org/10.1007/978-3-642-26010-0_4

[3] F. Alsharif, J. Tamura, S. Tamaki, K. Anupa, M. Futami, "Dynamics modification of passive pitch control for small-scaled wind turbine" Grand Renewable Energy 2018, Yokohama, Japan, June 2018. https://doi.org/10.24752/gre.1.0_147

[4] F. Asharif, S. Tamaki, H. Teppei, T. Nagado, T. Nagata, "Feasibility confirmation of angular velocity stall control for small-scaled wind turbine system by phase plane method" IEEK Transactions on Smart Processing and Computing, 2(4), 240-247, 2013.

[5] F. Asharif, S. Tamaki, T. Nagado, M. R. Alsharif, "Comparison and evaluation of restrain control in wind turbine with various shock absorber considering the time-delay" International Journal of Control and Automation, Vol. 5(3), 111-131, September 2012.

[6] F. Asharif, M. Futami, S. Tamaki, T. Nagado, K. Asato, "Stability and performance analysis of passive and active stall control of small-scaled wind turbine system by phase plane method" Proceedings of IEEE, International Conference on Intelligent Information and BioMedical Sciences (ICIIBMS 2015), .27-33, OIST, Okinawa, Japan, November 2015. https://doi.org/10.1109/ICIIBMS.2015.7439483

[7] M.Entezami, S.Hillmansen, P.Weston, M.Ph.Papaelias "Fault detection and diagnosis within a wind turbine mechanical braking system using condition monitoring" Renewable energy, 47, 175-182, November 2012. https://doi.org/10.1016/j.renene.2012.04.031

[8] A Koswatta, F Alsharif, Y Shiroma, M Khosravy, S Tamaki, J Tamura, "Alternative braking method for small-scaled wind turbines connected DC green house with analogical experiment on blade destruction" Advances in Science, Technology and Engineering Systems Journal, 5(2), 500-511 (2020). https://doi.org/10.25046/aj050264

[9] A. Z. Mohamed, M. N. Eskander, and F. A. Ghali, "Fuzzy logic controlbased maximum power tracking of a wind energy system," Renew. Energy, 23(2), pp. 235-245, Jun. 2001. https://doi.org/10.1016/S0960-1481(00)00099-9 
[10] H. Zhao, Q. Wu, C. N. Rasmussen, M. Blanke, "Adaptive speed control of a small wind energy conversion system for maximum power point tracking ", IEEE Trans. Energy Convers., 29(3), 576-584, Sep. 2014. https://doi.org/10.1109/TEC.2014.2312978

[11] K. Anupa, F. Asharif, S. Yasushi, K. Ken, S. Tamaki, J. Tamura, "Power analysis of eddy current brake system applied on small-scaled wind turbine for dc greenhouse" International Conference on Intelligent Informatics and Biomedical Sciences (ICIIBMS), Shanghai, China, 2019. https://doi.org 10.1109/ICIIBMS46890.2019.8991519

[12] K.J. Lee, K. Park, "Optimal robust control of a contactless brake system using an eddy current" Mechatronics, 9(6), 615-631, 1999. https://doi.org/10.1016/S0957-4158(99)00008-2

[13] J. D. Kraus, K. R. Carver, Electromagnetics, 2nd ed. McGraw Hill, 1973.

[14] D. Gubbins, E. Herrerobervera, ENCYCLOPEDIA of GEOMAGNETISM AND PALEOMAGNETISM, Springer, 2007.

[15] F. Asharif, S. Tamaki, T. Hirata, T. Nagado, T. Nagata, "Design of electromagnetic and centrifugal force pitch angle stall controller on application to small-scaled wind turbine system" International Symposium on Stochastic Systems Theory and Its Applications, 2013. https://doi.org/10.5687/sss.2014.231

[16] Y. Shiroma, H. Afuso, R. Suwa, A. Kinjo, Y. Tonooka, T. Kaga, Itaru. Nagayama, S. Tamaki, G. Maharjan, "Development of higher yield and highquality mango production system based on Internet of Things" IEEJ Transactions on Industry Applications, 139(2), 166-173, Feb. 2019. https://doi.org/10.1541/ieejias.139.166 